MATEC Web of Conferences 53, 01063 (2016)

DOI: $10.1051 /$ matecconf/20165301063

(C) Owned by the authors, published by EDP Sciences, 2016

\title{
Discretization Analysis in FEM Models
}

\author{
Giulia Martello ${ }^{1, a}$ \\ ${ }^{1}$ Università degli Studi di Brescia, Mechanical and Industrial Engineering Department, Brescia, Italy
}

\begin{abstract}
Discretization allows to switch from an infinite number of elements in a finite number and thanks to that the infinite degrees of freedom of the system become a finite number. The discretization of the domain consists of a subdivision into subdomains, which form a lattice or mesh. This work deals on different types of mesh and propose a choice for a specific problem.
\end{abstract}

\section{Introduction}

The discretisation [1-4] of the solution domain produces a numerical description of the computational domain [5-9]. The space is divided into a finite number of discrete regions or cells [10, 11], which form a mesh $[12,13]$.

This allows to switch from an infinite number of elements in a finite number and thanks to that the infinite degrees of freedom of the system become a finite number [14].

The discretization with Finite Element Method (FEM) [15-19] is based on the principle which is called with the latin expression "divide et impera" (thus "divide and rule"). This means that a complex problem is decomposed into many simpler problems, whose solutions lead to the solution of the general problem [20-23]. In this case the model of difficult solution is decomposed into many elements that can be solved more easily.

Alongside spatial discretization, also temporal discretization is, for transient simulations, fundamental as well, thus the time interval is also split into a finite number of time-steps [24-33]. This leads to less computational efforts and an analysis of smaller deformation of the general problem.

\footnotetext{
${ }^{\mathrm{a}}$ Corresponding author : giulia.mrt@gmail.com
} 


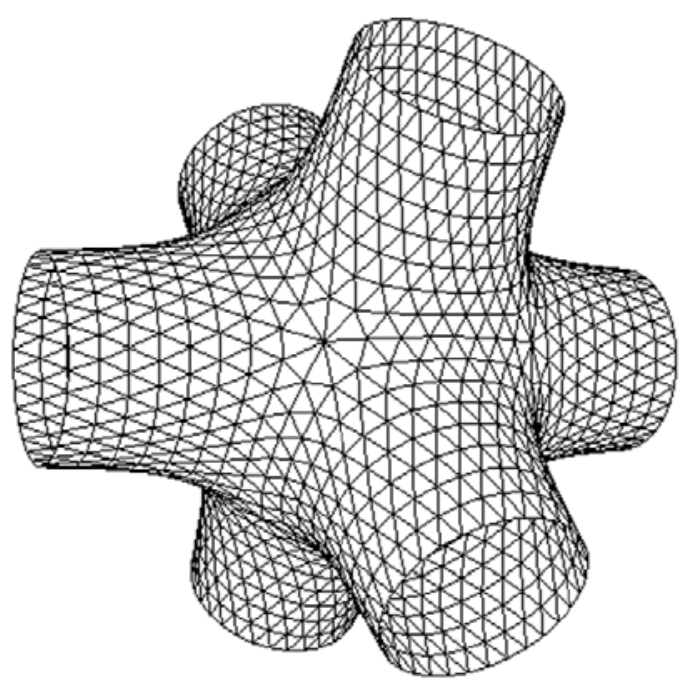

Figure 1. Mesh of a complex geometry.

The mesh generation is a fundamental step in the simulation because it is an integral part of the numerical solution and must satisfy certain criteria to ensure a valid, and hence accurate, solution [3439]. The mesh size [40-42] (defined for each direction and identified by the characteristic length $h$ ) has to be optimized [43-48], indeed it should be fine enough to make the problem easily resolvable and at the same time it has not to be too fine because the higher number of cells, the higher computational costs. Therefore the mesh density [49] depends also on the machine which is used for computations. After an accurate observation of the model shape and of gradients involved, a proper mesh can be obtained by refining it in the regions with physical needs, for example close to geometrical details that imply high gradients of the variable evaluated.

In the beam considered the variable which has a fundamental role is the stress component S12, parallel to the $y$ axis.

\section{Types of meshing}

Typically, cells used in FEM are simple geometric figures (in the one-dimensional problem segments, triangles or quadrilaterals in 2D problems, tetrahedrons or hexagonal in 3D problems). The topology is defined by special points called nodes.

The main types of cells that one can choose in a three-dimensional model follow.

- HEX: this type of elements are polyhedrons with 6 faces and quadrilateral faces, therefore these elements have 8 knots. An example of a mesh constructed by using these elements is shown in Figure 2.

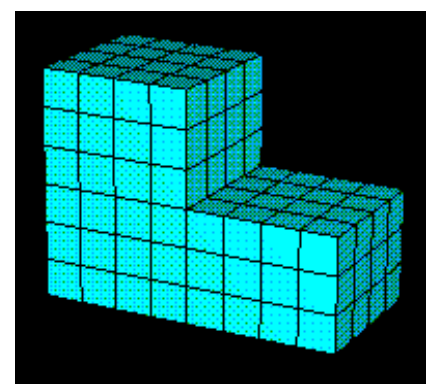

Figure 2. Mesh with cells type HEX. 
- HEX-dominated: HEX elements dominate, nevertheless it is also allowed to use some triangular base prisms (wedge) in the transition regions. An example in Figure 2.4.

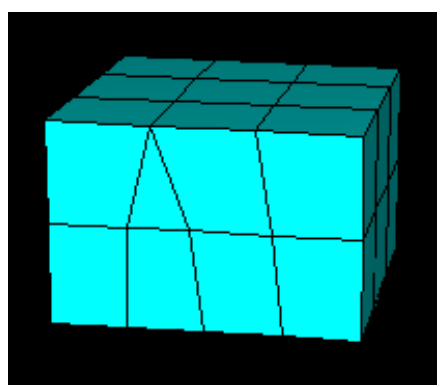

Figure 3. Mesh with HEX-dominated elements.

- TET: composition of elements only tetrahedral, thus with 4 knots, as shown in figure 4

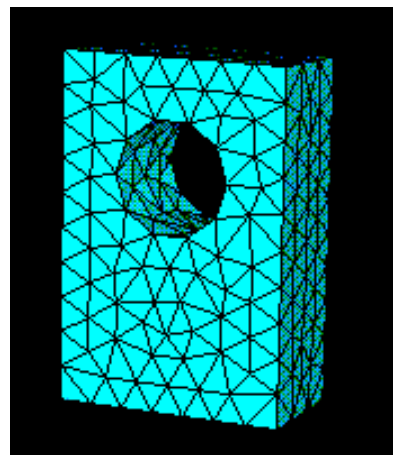

Figure 4. Mesh with tetrahedral elements.

- WEDGE: composition of wedge-shaped elements with 6 knots. More precisely, it refers to prisms with a triangular base, as shown in figure 5 .

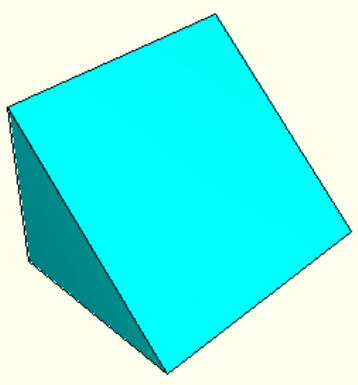

Figure 5. Element with WEDGE shape.

\section{Meshing effects and selection}

Given these four possible forms of item, one must choose the most appropriate geometry treated. It can be noted that HEX-dominated and HEX types differ only if the geometry is not completely 


\section{MATEC Web of Conferences}

regular; for example a triangular base prisms may appear if one uses this type of elements for a square plate with smoothed corner or with a hole in the middle. Since the geometry considered is extremely regular, this option is not taken into account. Also the tetragonal form of elements can be discarded, since these elements can be used to simplify a complex geometry but if the starting shape is already regular the use of these elements can lead to a more complicated problem. The more plausible possibilities are therefore HEX and WEDGE.

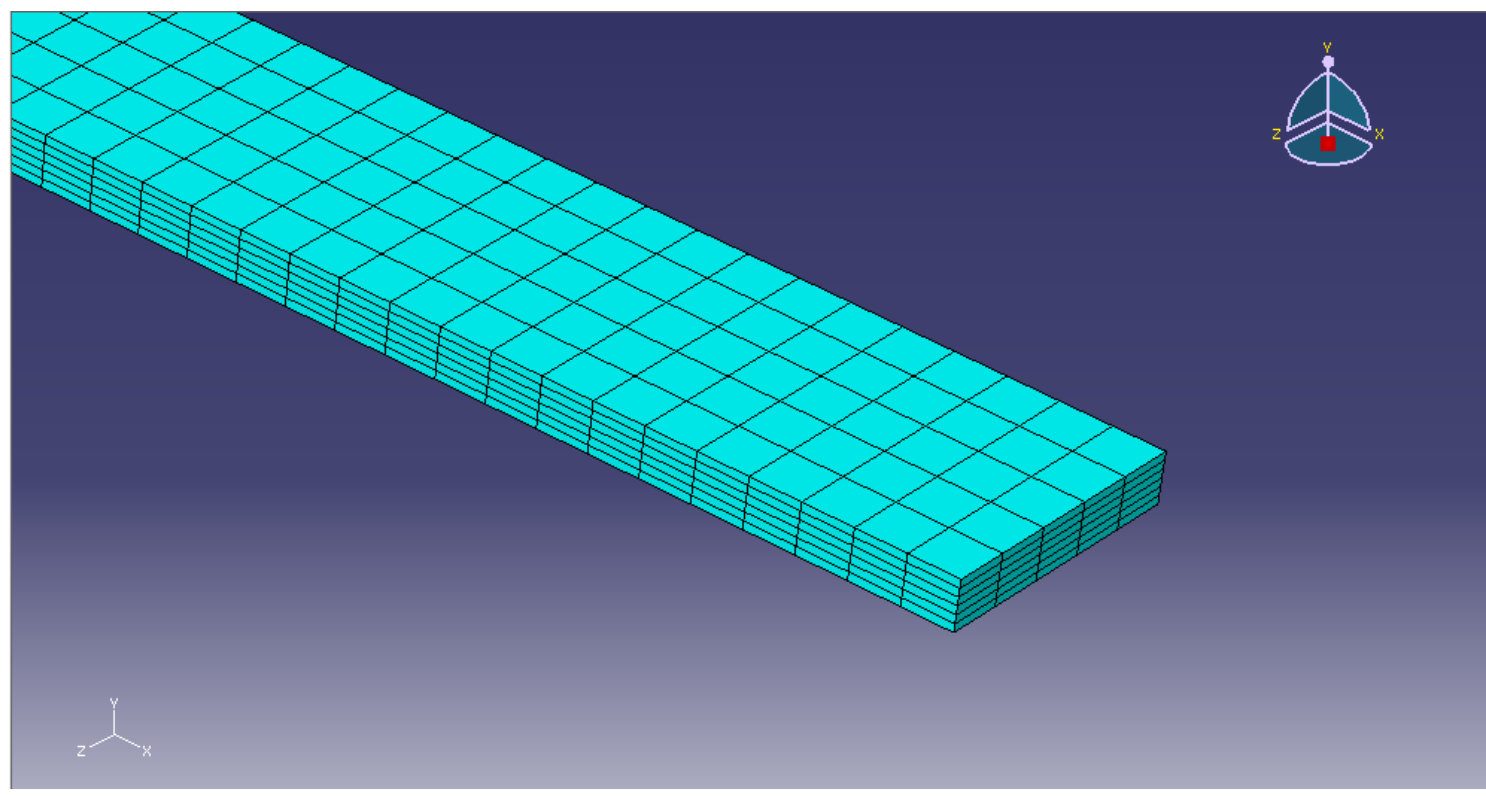

Figure 6. Discretization with HEX cells option.

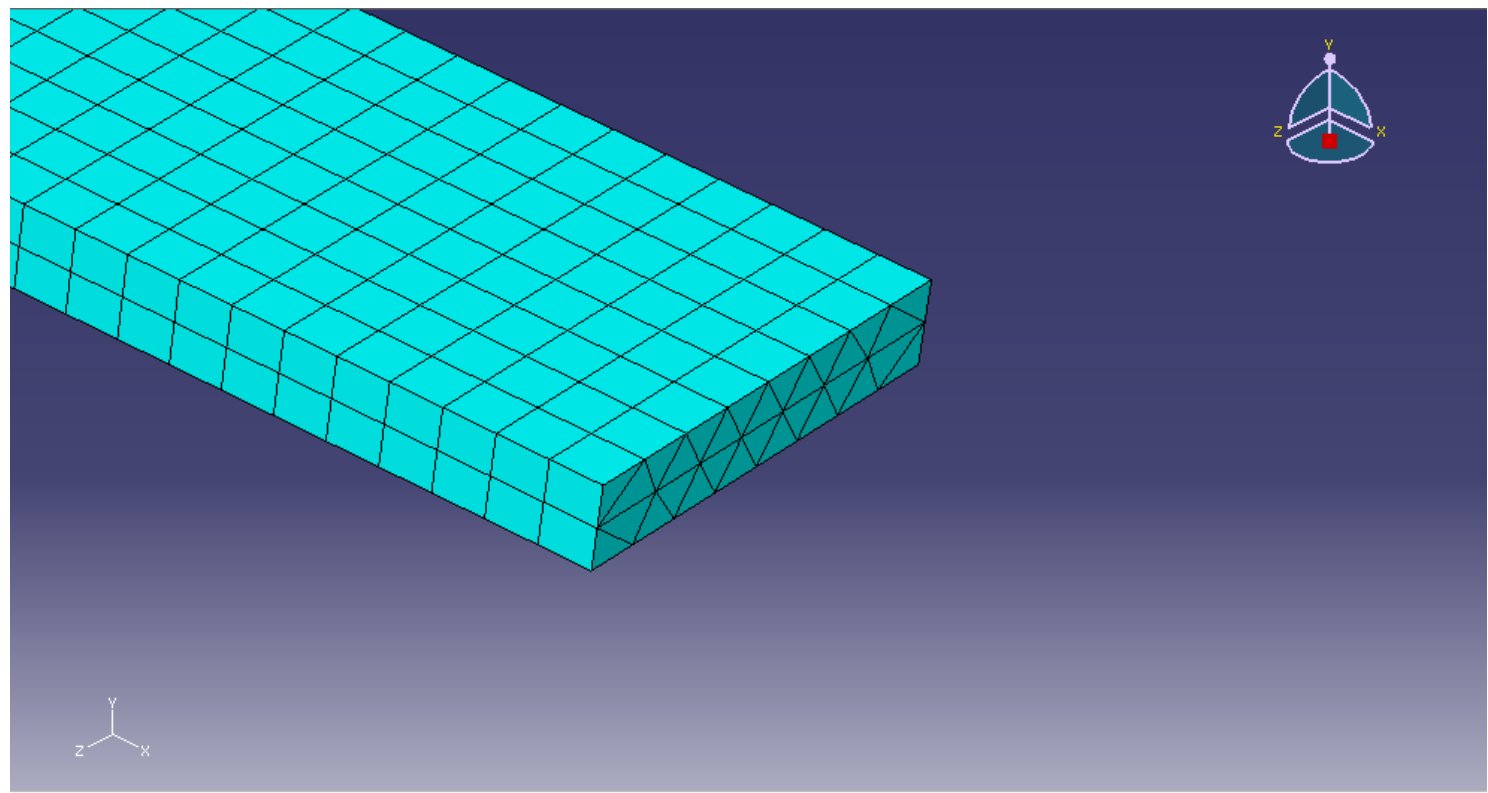

Figure 7. Discretization with WEDGE cells option. 
Concerning elements with triangular base, the concept explained regarding case tetrahedral is still true, even if to a lesser degree. Indeed, also WEDGE elements introduce some irregularity in a regular model.

HEX mesh, or in cubes or generic parallelepipeds, is the simplest and most intuitive mesh which perfectly reflects the geometry of the model. Nevertheless before approving it permanently also boundary conditions and loads must be taken into account, since they could make irregular stresses even if within a regular geometry.

As seen, the beam is analyzed by using a fixed joint at one end and the other end a load in axis with the symmetry axis of the beam is applied. The model then is symmetric also taking into account constraints and loads. It can therefore be assumed that the discretization with HEX cells does not limit the analysis on the beam.

Moreover, results obtained with the two types of meshes are comparable, since the sample tests carried out reveal an error of about $1 \%$.

Based on these considerations, it was decided to use a rectangular mesh (HEX type).

\section{Conclusions}

This work describes an introduction to the discretization problem and to different types of elements. Furthermore, after a discussion on different type of meshes, we propose a solution for a specific discretization problem.

\section{References}

[1] T. Nguyen-Van and N. Hori, Journal of Computational and Nonlinear Dynamics, 11, 2016

[2] A. Pascau and M. Arici, Computers and Fluids, 125, 101-115, 2016

[3] A. Borboni and D. De Santis, Meccanica, 49, 1327-1336, 2014

[4] A. Borboni, D. De Santis, and R. Faglia, ASME 2010 10th Biennial Conference on Engineering Systems Design and Analysis ESDA2010, 2, 99-106, 2010

[5] A. Caprara, M. Locatelli, and M. Monaci, Computational Optimization and Applications, 121,2016

[6] J. Gai, Z. H. Xia, and Q. D. Cai, Chinese Physics B, 24, 2015

[7] C. Amici, A. Borboni, and R. Faglia, Advances in Mechanical Engineering, 2, 1-9, 2010

[8] C. Amici, A. Borboni, P. L. Magnani, and D. Pomi, Proceedings of EUCOMES 2008 - The 2nd European Conference on Mechanism Science, 2008, 487-493, 2009

[9] C. Amici, A. Borboni, P. L. Magnani, and D. Pomi, Proceedings of EUCOMES 2008 - The 2nd European Conference on Mechanism Science, 2008, 479-485, 2009

[10] N. Nguyen-Minh, T. Nguyen-Thoi, T. Bui-Xuan, and T. Vo-Duy, Applied Mathematics and Computation, 266, 212-234, 2015

[11] M. H. Nguyen-Thoi, L. Le-Anh, V. Ho-Huu, H. Dang-Trung, and T. Nguyen-Thoi, Journal of Contemporary Physics, 50, 341-358, 2015

[12] M. Brdar and H. Zarin, Journal of Computational and Applied Mathematics, 292, 307-319, 2016

[13] Y. Yuan, R. Wang, J. Huang, Y. Jia, and H. Bao, Computers and Graphics (Pergamon), 54, $135-144,2016$

[14] A. Borboni, F. Aggogeri, N. Pellegrini, and R. Faglia, Advanced Materials Research, 590, 399-404, 2012

[15] A. Bautista, J. Montesinos, and P. Pintado, Mechanism and Machine Theory, 97, 100-111, 2016

[16] G. Buffa, J. Hua, R. Shivpuri, and L. Fratini, Materials Science and Engineering A, 419, 381388, 2006

[17] C. Farhat, Computers and Structures, 28, 579-602, 1988 
[18] A. Borboni, R. Faglia, and M. Mor, ASME 2014 12th Biennial Conference on Engineering Systems Design and Analysis ESDA 2014, 1, 1-10, 2014

[19] N. L. Vatin, J. Havula, L. Martikainen, A. S. Sinelnikov, A. V. Orlova, and S. V. Salamakhin, Advanced Materials Research 945-949, 1211-1215, 2014

[20] D. C. Rizos and Z. Wang, Engineering Analysis with Boundary Elements, 26, 877-888, 2002

[21] G. R. Liu, T. Nguyen-Thoi, H. Nguyen-Xuan, and K. Y. Lam, Computers and Structures, 87, 14-26, 2009

[22] A. Borboni, F. Aggogeri, and R. Faglia, International Journal of Advanced Robotic Systems, 10, 1-10, 2013

[23] A. Borboni, R. Faglia, and M. Palpacelli, MESA 2014 - 10th IEEE/ASME International Conference on Mechatronic and Embedded Systems and Applications, 1, 1-7, 2014

[24] X. Guan, B. Kang, N. Shu, Q. Yan, and Z. Li, Applied Computational Electromagnetics Society Journal, 30, 1223-1231, 2015

[25] W. Huang, S. Koric, X. Yu, K. J. Hsia, and X. Li, Nano Letters, 14, 6293-6297, 2014

[26] H. K. Kiran Kumar and D. Ajad, International Journal of Applied Engineering Research, 10, 44383-44386, 2015

[27] A. Borboni, F. Aggogeri, N. Pellegrini, and R. Faglia, Advanced Materials Research, 590, 405-410, 2012

[28] M. Tiboni, A. Borboni, M. Mor, and D. Pomi, Proceedings of the Institution of Mechanical Engineers. Part I: Journal of Systems and Control Engineering, 225, 443-451, 2011

[29] F. Aggogeri, A. Borboni, A. Merlo, and N. Pellegrini, Advanced Materials Research, 590, 252-257, 2012

[30] A. Borboni and M. Lancini, Journal of Vibration and Acoustics, Transactions of the ASME, 137, 1-9, 2015

[31] L. Muravyeva and N. Vatin, Applied Mechanics and Materials 635-637, 451-456, 2014

[32] S. Ognjenovic, R. Donceva, and N. Vatin, Procedia Engineering, 2015, 556-563

[33] N. Vatin, K. I. Strelets, and N. Kharkov, Applied Mechanics and Materials 635-637, 17-21, 2014

[34] D. L. Michels, J. P. T. Mueller, and G. A. Sobottka, Computers and Graphics (Pergamon), 53, 136-146, 2015

[35] J. Yan and D. Jiao, IEEE Antennas and Propagation Society, AP-S International Symposium (Digest), 2015, 342-343

[36] J. Yan and D. Jiao, IEEE Antennas and Propagation Society, AP-S International Symposium (Digest), 2015, 1830-1831

[37] A. Borboni, R. Bussola, R. Faglia, P. L. Magnani, and A. Menegolo, Journal of Mechanical Design, Transactions of the ASME, 130, 0823011-0823016, 2008

[38] C. Amici, A. Borboni, R. Faglia, D. Fausti, and P. L. Magnani, IEEE/RSJ International Conference on Intelligent Robots and Systems IROS, 2008, 735-740, 2008

[39] F. Aggogeri, A. Borboni, R. Faglia, A. Merlo, and S. De Cristofaro, Applied Mechanics and Materials, 336-338, 1170-1173, 2013

[40] E. Ágoston-Szabó, K. Schöll, A. Kiss, and M. Dinka, Hydrobiologia, 1-16, 2015

[41] P. K. Pandey and B. D. Pandey, Boletim da Sociedade Paranaense de Matematica, 34, 9-27, 2016

[42] C. Wendeler and A. Volkwein, Natural Hazards and Earth System Sciences, 15, 2597-2604, 2015

[43] Y. Sakamoto, Y. Bonkobara, T. Kondou, K. Abe, and T. Taniguchi, Nihon Kikai Gakkai Ronbunshu, C Hen/Transactions of the Japan Society of Mechanical Engineers, Part C, 77, 4367-4381, 2011

[44] S. Wei, Z. Lei, and Q. Du, Jixie Qiangdu/Journal of Mechanical Strength, 32, 859-864, 2010

[45] A. Borboni and R. Faglia, Procedia Engineering, 2014, 1378-1381

[46] F. Aggogeri, A. Borboni, and R. Faglia, Applied Mechanics and Materials, 373-375, 130133,2013 
[47] A. Borboni and R. Faglia, Journal of Applied Mechanics Transactions ASME, 80, 1-7, 2013

[48] M. Adjemout, N. Brunetiere, and J. Bouyer, Proceedings of the Institution of Mechanical Engineers, Part J: Journal of Engineering Tribology, 229, 1132-1144, 2015 